\section{Fundamentals of Geriatric Pharmacotherapy: An Evidence-Based Approach}

Hutchinson LC, Sleeper RB, editors. American Society of Health-System Pharmacists, Bethesda, Maryland, 2010. ISBN 9781-58528-228-9. Softcover, 463 pages. US $\$ 61$ for ASHP members (US\$68 for nonmembers).

Although a number of textbooks for geriatric medicine are available, few resources focus on geriatric pharmacotherapy. Similarly, the most commonly used pharmacy texts may have just one chapter, if any, on geriatrics, and the most recent edition of Therapeutics in the Elderly was published in 2003 (by Harvey Whitney Books Company). This situation makes the new text edited by Hutchinson and Sleeper particularly valuable for current pharmacy practice.

The book is divided into 2 sections. The first section, entitled "Social, Ethical, and Economic Issues of Aging", tackles issues such as challenges in geriatric care, care-giving, decisionmaking, and end-of-life care. Other textbooks in geriatrics provide comprehensive reviews of all of the topics. Fundamentals of Geriatric Pharmacotherapy provides summaries that are brief, but current and relevant. For example, the topic of elder abuse is condensed to 1 page.

The second section, entitled "General Biomedical and Pharmacotherapy Issues”, contains 14 chapters. The first 4 of these chapters relate to general geriatric practice (e.g. geriatric assessment), and the remaining chapters relate to specific systems or specialties (e.g., cardiology). Each chapter opens with learning objectives and definitions. References are included at the end of each chapter, in contrast to some of the leading geriatric texts, which provide only brief bibliographies. At the end of each chapter, there is a set of self-assessment questions, which vary in format. Chapter summaries and clinical pearls are also included.

What makes this text stand out is its use of case studies and application of information throughout each chapter. The case studies are complex and realistic, each covering 1 to 2 pages. A summary of each case is included, and key learning points are highlighted. The cases involve settings such as continuing care centres and conditions such as urinary incontinence, cachexia, dysphagia, and sensory impairment. These are common geriatric challenges that are rarely addressed in general pharmacy texts.

Most of the content is specific to the elderly population, but some chapters include general information, such as categories of adverse events, a list of abbreviations that should not be used, or the epidemiology of disease states for the general population. These topics should be familiar to most pharmacists or could be obtained from other general practice texts.

Readers might find it challenging to locate some of the information in the book. For example, vaccination is covered in the respiratory chapter (there is no infectious diseases chapter), erectile dysfunction appears under endocrinology (rather than urology), and the topic of pain is covered in several different chapters.

The editors and most of the authors are well-known experts in geriatrics. As can be expected for a book published by ASHP, the editors and authors are US practitioners, and the anticipated audience is American. Only US guidelines are referenced, and the book does not use SI units. However, international literature is cited throughout the text.

Practitioners will find the text easy to navigate. The content focuses on therapeutics, and pharmacists will sense that they represent the primary audience. The text will be useful for teaching, both in the classroom and in practice. For those already working in geriatrics, the book will provide a useful overview. This text, surprisingly inexpensive, would be a valuable resource for any health professional in geriatrics, particularly pharmacists.

Cheryl A Sadowski, BSc(Pharm), PharmD, FCSHP

Faculty of Pharmacy and Pharmaceutical Sciences

University of Alberta

Edmonton, Alberta 